\title{
Effect of mesh count on dot design and quality of screen printing in knit fabric
}

\begin{abstract}
Mesh count effect on the design and quality of printed fabric in screen printing was investigated after printing dot design on knit fabric using different mesh count screens and different types of ink. The design effect was evaluated by visual assessment as well as microscopic observation. Mesh opening area of each screen type was calculated from respective digital microscope images to find the possibility of the amount of ink passing through the screen and level of print detail, produced in dot design on the screen. Also, print coverage, saw-tooth effect, line sharpness, etc. were examined by measuring different distances, the diameter of dots, etc. in printed fabric and were compared with image positives. The quality of the printed fabric was assessed by color difference, color fastness.
\end{abstract}

Keywords: mesh count, dot design, screen, screen printing, gradation of tone, saw tooth effect, printing quality
Volume 6 Issue 4 - 2020

\author{
Rasheda Begum Dina,' Md Zulhash Uddin,' \\ Ummul Khair Fatema ${ }^{2}$ \\ 'Department of Wet Process Engineering, Bangladesh University \\ of Textiles, Bangladesh \\ ${ }^{2}$ Department of Environmental Science and Engineering, \\ Bangladesh University of Textiles, Bangladesh
}

Correspondence: Rasheda Begum Dina, Assistant Professor, Department of Wet Process Engineering, Bangladesh University of Textiles, 92, Shaheed Taj Uddin Ahmed Avenue, Tejgaon, Dhaka-I208, Bangladesh, Tel +8801913518137,

Email dina_butex@yahoo.com

Received: July 05, 2020 | Published: July 222020

Abbreviations: MC, mesh count; GSM, gram per square meter, HW, high weight; LW, low weight

\section{Introduction}

Screen printing is an extension of stenciling. Innumerable children experiment with simple stencils by cutting out shapes from cards, and brushing or spraying paint or ink through the holes on paper beneath. Commercial stencil sets for lettering are made of waxed card or metal, and incorporate ties to hold the solid areas together and to prevent the centers of letters such as $\mathrm{O}$ or $\mathrm{P}$ from falling out. The ties produce unsightly lines across the stenciled letters. ${ }^{1}$

Standard polyester fabrics make ideal stencil material for screen printing. Precision weaving techniques, using state-of-theart equipment optimized for screen printing applications, results in excellent fabric quality. Polyester fabrics woven from high-viscosity polyester are a further development of standard polyester fabrics. The material's reduced elasticity enhances the already good properties of standard fabrics. These stencil fabrics offer increased process reliability, and significantly higher tensioning that is retained over large print runs and long periods of time.

Polyamide fabrics (nylon) have exceptional mechanical durability. This makes them highly suitable for printing abrasive media (ceramic colors, reflective inks). The stencil fabric's high elasticity makes it easier to print uneven. The terms "mesh type" or "fabric number" is similar descriptions of the mesh count per centimeter/inch. ${ }^{2}$

There are three general types of textile inks. They are-- traditional solvent-based inks, water-based inks and plastisol inks. The two inks used most often in textile printing are water-based and plastisol.

The solvent in solvent based ink has two primary functions that one to carry the ink to the substrate, and another is to evaporate quickly, leaving only the ink film on the substrate. While water is a solvent, the name solvent-based ink is used to describe a highly volatile solvent such as 2-butoxyethyl acetate, cyclohexanone and n-butyl acetate.

Solvent based inks are considered the least environmentally friendly due to the highly volatile solvents given off during printing and drying. The petroleum-based binder used in many solvent-based inks could be replaced with renewable resources such as vegetable oil or soy. The downsides are that the inks dry very slowly are less durable, and still contain solvents emitting VOCs during printing.

There are now inks on the market called eco solvent inks. To most people, "eco" means ecological, and to be fair these inks are not as nasty as full solvent inks. But these inks generally contain glycol esters or glycol ether esters - both derived from mineral oil - hardly a renewable resource or an ecologically sound process.

Water-based inks use water as the main solvent. But that does not mean that water is the only solvent used. Many water base inks contain "co-solvents" which may even be petroleum-based solvents. The reasons these co-solvents are used vary, but a main reason is to decrease the time and heat necessary to cure the ink on the fabric.

These inks are inexpensive and easy to manufacture.

Plastisol inks, commonly used for textile printing and especially for t-shirts, are a PVC-based ink composed of a clear, thick plasticizer fluid and PVC resin. The full name for PVC is polyvinyl chloride. The PVC life cycle results in the release of toxic, chlorine-based chemicals which end up as by-products such as carcinogenic and highly toxic dioxin and PCB. The major health concern about Plastisol inks is not that they are PVC-based but that they contain phthalates. Phthalates are added to PVC plastics to transform a hard plastic into a soft, rubbery plastic by allowing the long polyvinyl molecules to slide against each other instead of rigidly binding together. ${ }^{3}$

Screen printing is one of the most cost-effective methods in today's printing market. The screen printing method has long been the standard for knit printing. This printing method is actually relatively easy to print on whatever we want than other printing methods in comparison with time, cost, accuracy, production rate, but for getting correct design with proper print detail, resolution, coverage, hand feel etc. we should select the correct mesh count and ink system for a specific type of design. 
The amount of print paste passing through the screen can be controlled by the mesh (threads/inch) of the screen fabric. Generally, a coarse mesh allows more paste to pass through than a fine one. ${ }^{4}$

In many screen-printed fabrics the edges of the printed areas appear serrated, although they were smooth curves or straight lines at the color separation stage. This is known as the 'saw tooth effect' and is an almost inevitable consequence of the design area consisting of a regular array of threads and spaces. ${ }^{5}$

The dot is the key factor for the printing quality. It determines the color of the printing sample, the gradation of image and image color. Screen printing is a printing technique that uses woven mesh to support an ink-blocking stencil. . $^{6,7}$

The higher the mesh count and more smooth printing material can induce the better dot, tone reproduction and higher printing precision.

The research work was carried on printing under the different mesh count screen for dot design with different ink to relate the effect of mesh count on cotton knit printed fabric and assessment of printing quality.

\section{Materials and methods}

\section{Materials}

Fabrics: $100 \%$ cotton fabric of the $1 \times 1$ rib structure, GSM 200 and 180 were purchased from Micro Fiber Limited, Rambagh, Kutubpur, Fatullah, Naryanganj, Bangladesh. Fabric specifications are given in Table 1. Fabrics are pretreated in lab with the recipe given in Table 2 and Table 3. After pretreatment, fabrics are printed by the five different inks.

Table I Types of fabric with specification

\begin{tabular}{llll}
\hline Fabric & Knit structure & GSM & Composition \\
\hline HG & $\operatorname{RIB}(|\times|)$ & 200 & $100 \%$ cotton \\
LG & $\operatorname{RIB}(|\times|)$ & 180 & $100 \%$ cotton \\
\hline
\end{tabular}

Table 2 Pretreatment recipe

\begin{tabular}{llll}
\hline \multicolumn{3}{l}{ Pretreatment (scouring \& bleaching) } \\
\hline Chemical name & Dosing & Quantity & Fabric Wt.45.8kg \\
\hline KS-90 & $1.30 \mathrm{~g} / 1$ & $0.390 \mathrm{~kg}$ & \\
INSA & $0.25 \mathrm{~g} / 1$ & $0.075 \mathrm{~kg}$ & \\
CAN & $0.65 \mathrm{~g} / 1$ & $0.0195 \mathrm{~kg}$ & $98^{\circ} \mathrm{C}^{\prime} 50 \mathrm{Min}$ \\
CBA & $0.65 \mathrm{~g} / 1$ & $0.195 \mathrm{~kg}$ & \\
Stabilizer & $0.22 \mathrm{~g} / 1$ & $0.066 \mathrm{~kg}$ & \\
Caustic soda & $1.80 \mathrm{~g} / 1$ & $0.540 \mathrm{~kg}$ & \\
Hydrogen per & $1.75 \mathrm{~g} / 1$ & $0.525 \mathrm{~kg}$ & \\
oxide (50\%) & &
\end{tabular}

Printing inks: Five types of printing inks are used for the experiment. Three of these inks are water based, one is solvent based and another is plastisol based. Both solvent-based ink NYE 100 (black) and plastisol based ink ONP 124 (red, free from phthalate) are ready paste while rest of three inks named RYUDYE-W KN WHITE P-75 RYUDYE-W KN CLEAR P-76 (acrylic polymer), Stretch White 301-
1 (acrylic resin) Clear 301C-J-1 and NEWTEX BIF New (pigment printing agent) are not ready paste. All inks were taken from Dysin Chemicals Ltd. The printing recipes are given in Table 4.

Table 3 Per oxide killing \& enzyme treatment

\begin{tabular}{llll}
\hline $\begin{array}{l}\text { Chemical } \\
\text { name }\end{array}$ & Dosing & Quantity & Fabric Wt.45.8kg \\
\hline A.ACID & $0.80 \mathrm{~g} / 1$ & $0.24 \mathrm{~kg}$ & \\
OEN & $0.30 \mathrm{~g} / 1$ & $0.09 \mathrm{~kg}$ & \\
DL & $0.25 \mathrm{~g} / 1$ & $0.115 \mathrm{~kg}$ & \\
\hline
\end{tabular}

Table 4 Printing recipe

\begin{tabular}{llll}
\hline Ingredients & $\begin{array}{l}\text { Ingredients } \\
\text { composition }\end{array}$ & $\begin{array}{l}\text { Used } \\
\text { amount }\end{array}$ & Viscosity \\
Water based ink & $\begin{array}{l}\text { RYUDYE-W KN } \\
\text { WHITE }\end{array}$ & $90 \%$ & 95000 \\
& P-75 (=40\%) & & \\
& RYUDYE-W KN \\
& CLEAR & & \\
& P-76(=60\%) &
\end{tabular}

RYUDYE-W

COLOUR

Water based ink $10 \%$

Stretch White 30I$\mathrm{I}(=40 \%)$ and Clear $\quad 90 \%$ 130000 30 I C-J-I (=60\%)

\begin{tabular}{|c|c|c|c|}
\hline Neo Color pigment & - & $8 \%$ & \\
\hline Fixer $\mathrm{F}$ & - & $2 \%$ & \\
\hline \multicolumn{4}{|l|}{ (or Fixer $\mathrm{N}$ ) } \\
\hline $\begin{array}{l}\text { Water based ink } \\
\text { (NEWTEX BIF) }\end{array}$ & - & $90 \%$ & 80000 \\
\hline Printing Color & - & $10 \%$ & \\
\hline $\begin{array}{l}\text { Solvent based } \\
\text { ink(NYE I00) }\end{array}$ & Ready paste & $100 \%$ & 7800 \\
\hline $\begin{array}{l}\text { Plastisol based ink } \\
\text { (ONP I 24) }\end{array}$ & Ready Paste & $100 \%$ & 200000 \\
\hline
\end{tabular}

Mesh fabrics: Polyester monofilament mesh fabric of plain weave with 43, 61 and 120 mesh count was purchased from Dysin-Chem Limited, Dhaka, Bangladesh. A screen printing frame consists of an aluminum frame stretched with mesh fabric on it. Aluminum frame was stretched with polyester mesh fabric on it by a pneumatic system for making a flat screen. Dot designs were created on the types of mesh screen. Mesh specification is given in Table 5.

\section{Chemicals}

Pretreatment chemicals: Having purchased Standard soap, Sequestering Agent INSA, Wetting Agent KS-90, Hydrogen Peroxide, Stabilizer, Alkali, acetic acid, Enzyme-DL, Anti-Creasing Agent CAN; CBA, Per Oxide Killer OEM chemicals from Orient Chem-Tex 
Limited were used for scouring and bleaching of the fabrics before printing according to the recipe given in Table 2 and Table 3 .

Table 5 Types of mesh with specification

\begin{tabular}{llll}
\hline Mesh count & Weave & Filament type & Raw materials \\
\hline 43 & Plain & Mono & Polyester \\
61 & Plain & Mono & Polyester \\
120 & Plain & Mono & Polyester \\
\hline
\end{tabular}

Screen preparation chemicals: Emulsion photo cure TXR, Adhesive SFX001, and catalyst SFX002 AT were purchased from Dysin-Chem Limited. Emulsion photo cure TXR was used during the coating of screen mesh fabric and Adhesive SFX001 and catalyst SFX002 AT were used during attachment of mesh fabric with the aluminum frame.

\section{Instrumentation}

Screen stretcher machine: The pneumatic stretching machine made by Murakami, Singapore was used for stretching mesh fabric before attaching to the aluminum frame. The mechanical stretching apparatus produces tension forces in the warp and weft directions. Pneumatic screen stretcher delivers high-tension stretching on virtually any mesh/frame combination. Max Newton's air cylinders compensate for variations in mesh elasticity and fully extend after tensioning. Warp and weft are independently tensioned and controlled, and the durable PVC-coated locking bar grip tightly without tearing mesh.

Tension meter: A Murakami Tension Meter was used for recording tensions.

Screen drying machine: Screen Drying Machine, Murakami, was used for drying screen after emulsion coating.

UV exposure: Murakami, used for exposing UV light on the image positive paper was set on emulsion coated screen.

Screen printing machine: Screen printing machine, Shenzhen Quan Tong Screen Printing Machinery Co., Ltd., Shenzhen China, was used for fabric printing.

Curing machine-Curing machine, NOR, was used for fixation of printing paste after printing process.

Viscometer: Viscometer, Brookfield, was used to measure the viscosity of printing paste.

Spectrophotometer and color matching software: Datacolor 650 Spectrophotometer (Dual beam reflectance spectrophotometer) and color matching software (Datacolor, USA) from Testing Lab of Orient Chem-Tex Limited were used for measuring color values.

Gyro wash machine: Gyro wash of James H. Heal Co. Ltd, Halifax, English was used for wash fastness testing.

Crock meter: Digital Crock meter of Fang Yuan Instrument Co., Ltd, Shenzhen, China was used for rubbing fastness testing.

Light fastness tester: Microsol light fastness tester of James H.Heal, Halifax, England was used for light fastness testing.

Digital microscope: USB digital microscope, with high resolution image sensor, made in China, supplied from Dysin Chemicals Ltd. was used for observing the microscopic view of mesh screen, emulsion coated mesh fabric, and printed area of cotton fabric.

Lab temperature humidity control chamber: Fang Yuan Instrument Co. Ltd, Shenzhen, Chaina was used for conditioning printed sample.

\section{Methods}

Screen preparation: At first artwork or design was prepared. Dot designs were selected and their film positive was created. For dot design, 43, 61 and 120 mesh count screens were used. Tension is measured in Newton per $\mathrm{cm}(1 \mathrm{~N}=0.102 \mathrm{KP})$ with a tension meter placed on the mesh fabric. The screen was attached with a frame by adhesive SFX001 and catalyst SFX002 AT 17 Newton per cm.

Before coating the mesh, it was cleaned with a special screenprinting degreaser (screen solve) so that the emulsion sticks to it and dried at $55^{\circ} \mathrm{C}$ for five minutes. Screen was coated with photo cure TXR and dried, got film positive, aligned it to the screen, and exposed it with a screen-printing exposure unit for 10 seconds. The screen was hardened to light, but the positive or black area of the film blocked the light from reaching the emulsion, this left that area of the emulsion unexposed. After that screen was washed by normal water and dried at $55^{\circ} \mathrm{C}$.

\section{Pretreatment (scouring and bleaching)}

Cotton fabric was pretreated by the recipe given in Table 1 .

Printing : Before printing, the screen and frame are lined with a tape. It was checked blocking out any unwanted 'pin-holes' in the emulsion. Fabrics are lightly gummed at the top of the printing plate. The screen was set on the machine. Printing paste was kept on the screen and the machine was switched on. Printing was done by constant squeeze pressure and $45^{\circ}$ squeeze angle. Thirty samples were prepared by three mesh screens; each screen was used to print on two types of fabric by five different print inks.

Curing: Curing was done at $150^{\circ} \mathrm{C}$ for five minutes for fixation of printing ink.

Weight measurement: Printed and unprinted fabric was cut in a certain dimension for a specific design. The dimension was selected according to the printed area. Ink deposition weight was got by the difference of printed and unprinted fabric weight. All the weight was taken after conditioning the fabric for four hours at $65 \%$ relative humidity and $20^{\circ} \mathrm{C}$ temperatures. Weight was taken by electronic balance.

Color co-ordinates of printed sample: The color coordinates of the samples were measured based on the CIELAB system by dual beam reflectance spectrophotometer using color-matching software (Data color international, USA). ${ }^{9}$

Printed fabric analysis under digital microscope: At first the Gaosuo software was installed on the computer from a CD. The digital microscope was kept with a stand and connected via wire to the USB port of the computer. A screen was opened on a computer. Before capturing picture camera size was selected. There were five camera sizes. In the thesis work one camera size $(1600 \times 1200$ pixels) was used. Printed fabric was kept under the microscope and clicked the capture option to capture the image. Capturing image was stopped after clicking on stop option. The image was stored in the microscope and program files also. Captured picture was selected for measurement in turn. Distance, circular area, diameter, rectangle area, etc. was measured by selecting different options of measurement. 
Then the picture was saved in the computer.

\section{Color fastness}

Washing fastness: Washing fastness test was carried out following ISO 105 C02 method. ${ }^{10}$

Light fastness test: Light fastness test was carried out by ISO 105B02 method. ${ }^{11}$

Rubbing fastness: Rubbing Fastness test was carried out by ISO $105 \times 12$ method. ${ }^{12}$

\section{Results and discussions}

\section{Calculation of open area percentage of mesh count fabric in $1600 \times 1200$ pixels}

It took $6 \times 6 \mathrm{~mm}^{2}$ area of mesh fabric for calculating open area under the microscope at camera size $1600 \times 1200$ pixels. For every mesh count, number of open rectangles was counted and percentage of open area was calculated by the following formula.

Average rectangle area $=\frac{\sum(\text { Total open rectangle area })}{(\text { number of open rectangle area })}$

Percentage of open area $=\frac{\text { Average rectangle area }}{36} \times 100$

36

In mesh count 43 (Figure 1a), there were 4 open rectangle area and the area of open rectangles were as below:

The area of open rectangles $\left(\mathrm{mm}^{2}\right)$
$2.808 \quad 2.25 \quad 2.688$
2.24

and the average of rectangle open area was $2.4965 \mathrm{~mm}^{2}$. Total open area was $9.845 \mathrm{~mm}^{2}$.

In mesh count 61 (Figure 1b), there were nine open rectangle area.

The area of open rectangles $\left(\mathrm{mm}^{2}\right)$

$\begin{array}{llllll}0.81 & 0.739 & 0.739 & 0.768 & 0.773 & 0.739 \\ 0.774 & 0.634 & 0.638 & & & \end{array}$

and the average of rectangle open area was $0.734 \mathrm{~mm}^{2}$.Total open area was $6.614 \mathrm{~mm}^{2}$.

In mesh count 120 (Figure 1c), there were thirty-six open rectangle area. The area of open rectangles was as below:

The area of open rectangles $\left(\mathrm{mm}^{2}\right)$

$\begin{array}{llllll}0.144 & 0.102 & 0.115 & 0.101 & 0.067 & 0.102 \\ 0.115 & 0.115 & 0.115 & 0.115 & 0.128 & 0.144 \\ 0.101 & 0.086 & 0.112 & 0.09 & 0.128 & 0.09 \\ 0.115 & 0.101 & 0.141 & 0.102 & 0.078 & 0.128 \\ 0.123 & 0.101 & 0.09 & 0.058 & 0.019 & 0.04 \\ 0.045 & 0.102 & 0.064 & 0.144 & 0.144 & 0.096\end{array}$

and the average of rectangle open area was $0.144 \mathrm{~mm}^{2}$. Total open area was $4.47 \mathrm{~mm}^{2}$ (Table 6) (Figure 2) (Figure 3).

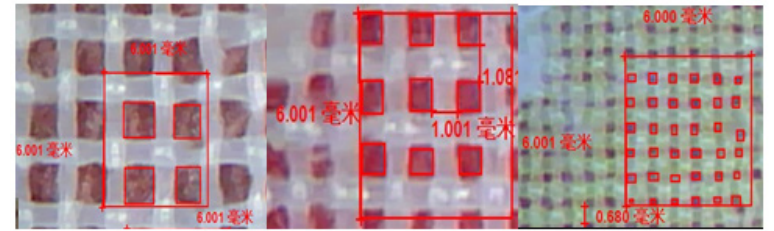

(a) Mesh count 43 (b) Mesh count 61 (c) Mesh count 120

Figure I Images of mesh fabric used in different screen (at camera size $1600 \times 1200$ pixels).

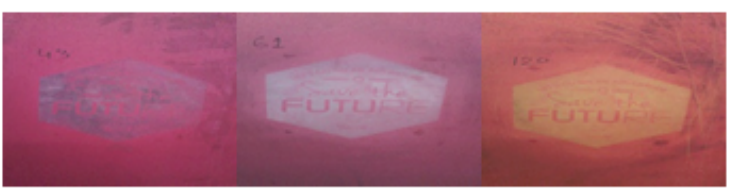

MC 43 screen MC 61 screen MC 120 screen

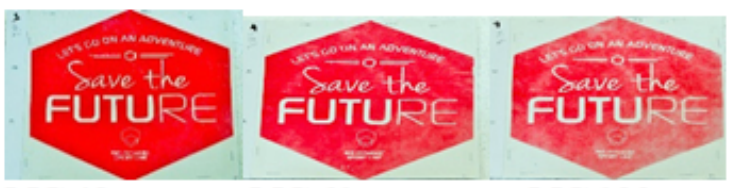

MC 43 screen MC 61 screen MC 120 screen

Printed Fabric by using ink P-75(40\%) P-76(60\%)
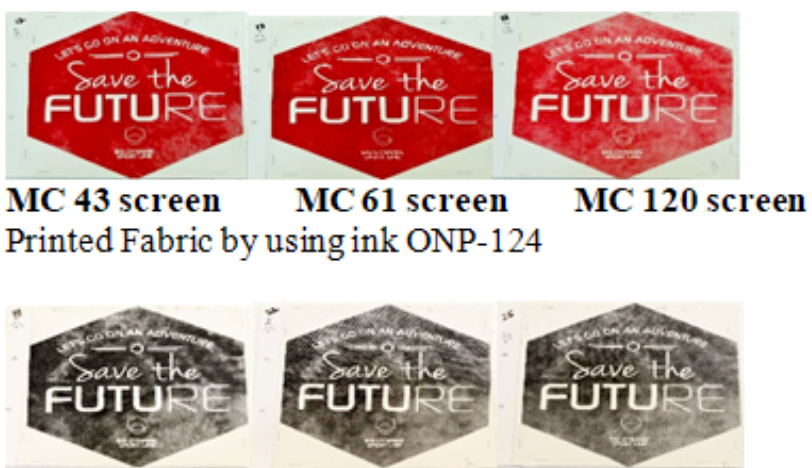

MC 43 screen MC 61 screen MC 120 screen

Printed Fabric by using ink NYE-100

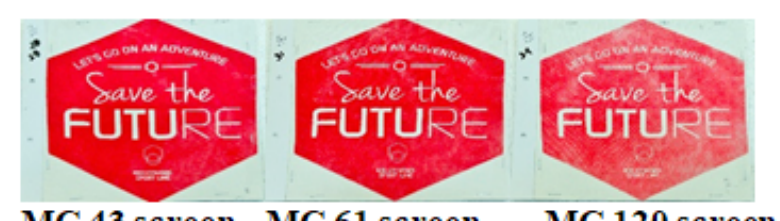

MC 43 screen MC 61 screen MC 120 screen

Printed Fabric by using ink 301-C-J-1(60\%) 301-SW-1(40\%)

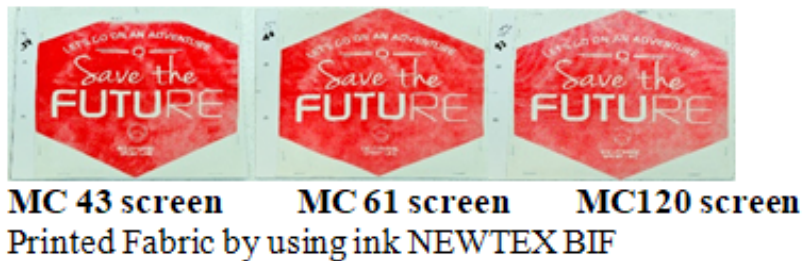

Figure 2 Dot design printed fabric (high GSM) with different mesh count screen by different inks. 


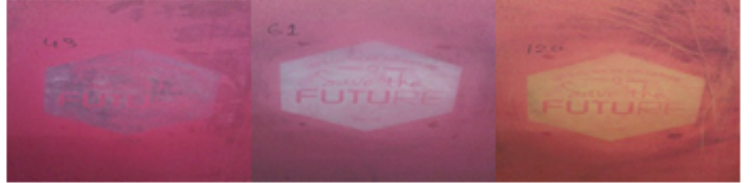

MC 43 screen MC 61 screen MC 120 screen

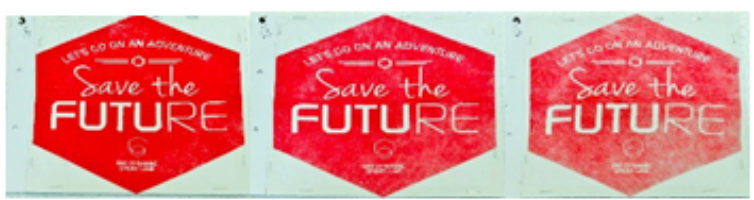

MC 43 screen MC 61 screen MC 120 screen

Printed Fabric by using ink P-75(40\%) P-76(60\%)

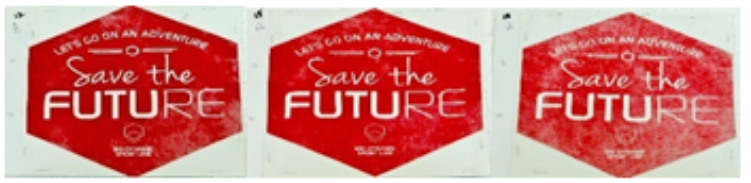

MC 43 screen MC 61 screen MC 120 screen

Printed Fabric by using ink ONP-124
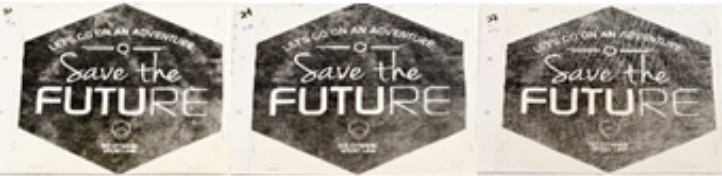

MC 43 screen MC 61 screen MC 120 screen

Printed Fabric by using ink NYE-100

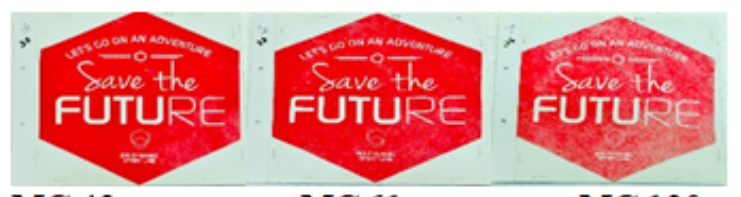

MC 43 screen MC 61 screen MC 120 screen

Printed Fabric by using ink 301-C-J-1(60\%) 301-SW-1(40\%)

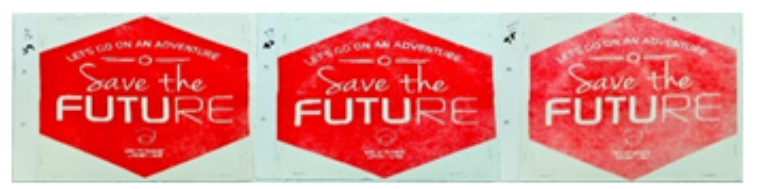

\section{43 screen MC 61 screen MC 120 screen}

Printed Fabric by using ink NEWTEX BIF

Figure 3 Dot design printed fabric (low GSM) with different mesh count screen by different ink.

\section{Visual assessment of printed fabric}

For visual assessment, we categorized the printed fabric, excellent (rating-7), very good (rating-6), good (rating-5), moderate (rating-4), bad (rating-3), very bad (rating-2), worst (rating-1) in background coverage, hand feel, gradation of tone and saw tooth effect (Table 7).

A lower mesh screen could not hold the high detail of design. The dots in the image were simply falling through the holes in the mesh not giving a correct representation of what the image should be.
The ink was flooding through the large open area in the low mesh count screen, making the image blurry as the ink bleeds.

The background coverage was good but lost print detail and also increased bad hand feelings as the ink was deposited in a high percentage for low mesh count screens.

The ink was deposited through the small open area with high mesh, making the appropriate image as the ink deposited preciously. The background coverage was not good, but got print detail in dot design, and also increased good hand feelings as the ink was deposited in low percentage for a high mesh count screen.

\section{Ink deposition on printed fabric}

At first printed and unprinted fabric was conditioned for four hours at temperature $20^{\circ} \mathrm{C}$ and 65 percent relative humidity. Then the samples were cut with same dimension for specific design and measured their weight by electronic balance.

The sample size was $\left(10^{\prime \prime} \times 9^{\prime \prime}\right)$. The ink deposition percentage was calculated by following formula

Percentage of link deposition $=\frac{\text { printed fabric weight-unprinted fabric weight }}{\text { unprinted fabric weight }} \times 100$

Rib(HW) and Rib(LW) was used to indicate high GSM and low GSM fabric.

In Table 8 , it can be observed that ink was deposited higher percentage in high GSM fabric than lower GSM. High viscous paste was deposited with more weight than lower viscous paste. The order was $\quad$ ONP $>$ CJ-1-301,SW-1-301 $>$ P75, P76 $>$ Pigment $>$ NYE from Figure 4, it found that more paste was deposited on printed fabric by high open area mesh count screen as the more open area pass more ink. The order was $43 \mathrm{MC}$ screen $>61 \mathrm{MC}$ screen $>120 \mathrm{MC}$ screen (Figure 4).

\section{Ink deposition percentage (dot design)}

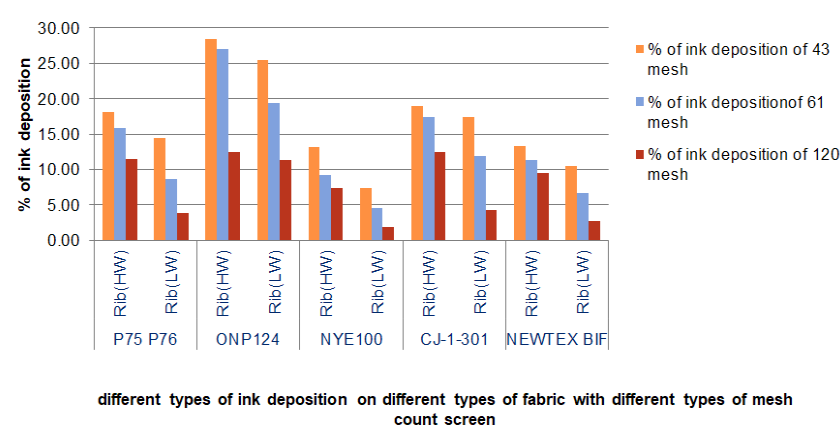

Figure 4 lnk deposition percentages (dot design).

\section{Color difference of different printed fabric with various mesh count screen}

From the Figure 5, color difference was observed with the change of the screen mesh count. Printed fabric was lighter in print with the higher mesh count screen than the lower mesh count screen. The reason was high in deposition causes less reflection than lower ink deposited surface as reflection was greater in lighter surface than darker surface. 
Table 6 Open area of mesh fabric in different screen count

\begin{tabular}{|c|c|c|c|c|c|c|}
\hline 43 & 4 & 2.4965 & 9.986 & 27.73 & 1.6 & 1.56 \\
\hline 61 & 9 & 0.734 & 6.614 & 18.37 & 0.56 & 0.6 \\
\hline
\end{tabular}

Table 7 Quality of dot printed fabric (visual assessment)

\begin{tabular}{|c|c|c|c|c|c|}
\hline Ink name & Mesh count & Background coverage & Gradation of tone & Saw tooth effect & Hand feel \\
\hline P-75(40\%) & 43 & Good & Very poor & good & Very bad \\
\hline \multirow[t]{2}{*}{ P-76(60\%) } & 61 & Moderate & moderate & moderate & bad \\
\hline & 120 & Very poor & good & Very poor & good \\
\hline \multirow[t]{3}{*}{ ONP-I 24} & 43 & Good & poor & good & Very bad \\
\hline & 61 & Moderate & moderate & moderate & bad \\
\hline & 120 & Very poor & good & Very poor & good \\
\hline \multirow[t]{3}{*}{ NYE-I00 } & 43 & Moderate & moderate & good & bad \\
\hline & 61 & Poor & good & moderate & good \\
\hline & 120 & Poor & good & Very poor & Very good \\
\hline 30 I-C-J-I(60\%) & 43 & Good & Very poor & good & Very bad \\
\hline \multirow[t]{2}{*}{ 30I-SW-I(40\%) } & 61 & Moderate & moderate & moderate & bad \\
\hline & 120 & Very poor & good & Very poor & good \\
\hline \multirow[t]{3}{*}{ Newtex BIF } & 43 & Moderate & moderate & good & good \\
\hline & 61 & Poor & good & moderate & good \\
\hline & 120 & Poor & good & Very poor & Very good \\
\hline
\end{tabular}

Table 8 Ink deposition percentage by different mesh screen

\begin{tabular}{|c|c|c|c|c|c|c|c|c|c|c|c|}
\hline \multirow[b]{2}{*}{ Ink Name } & \multirow{2}{*}{$\begin{array}{l}\text { Fabric } \\
\left(10^{2} 9^{2}\right)\end{array}$} & \multirow{2}{*}{$\begin{array}{l}\text { Fabric } \\
\text { Wt. } \\
\text { (gm) }\end{array}$} & \multicolumn{3}{|c|}{ For mesh:43 } & \multicolumn{3}{|c|}{ For mesh:6I } & \multicolumn{3}{|c|}{ For mesh:I 20} \\
\hline & & & $\begin{array}{l}\text { Fabric } \\
\text { wt with } \\
\text { Ink(gm) }\end{array}$ & $\begin{array}{l}\text { InkWt. } \\
\text { (gm) }\end{array}$ & $\begin{array}{l}\text { Percentage } \\
\text { of ink } \\
\text { deposition }\end{array}$ & $\begin{array}{l}\text { Fabric } \\
\text { wt with } \\
\text { Ink } \\
(\mathrm{gm})\end{array}$ & $\begin{array}{l}\text { Ink } \\
\text { Wt. } \\
\text { (gm) }\end{array}$ & $\begin{array}{l}\text { Percentage } \\
\text { of ink } \\
\text { deposition }\end{array}$ & $\begin{array}{l}\text { Fabric } \\
\text { wt } \\
\text { with } \\
\text { Ink } \\
\text { (gm) }\end{array}$ & $\begin{array}{l}\text { Ink } \\
\text { Wt. } \\
\text { (gm) }\end{array}$ & $\begin{array}{l}\text { Percentage } \\
\text { of ink } \\
\text { deposition }\end{array}$ \\
\hline P-75 (40\%) & $\operatorname{Rib}(\mathrm{HW})$ & II.887 & 14.037 & 2.15 & 18.09 & 13.775 & 1.888 & 15.88 & 13.249 & 1.362 & 11.46 \\
\hline P-76 (60\%) & $\operatorname{Rib}(L W)$ & II. .466 & 13.122 & 1.656 & 14.44 & 12.46 & 0.994 & 8.67 & 11.915 & 0.449 & 3.92 \\
\hline \multirow[t]{2}{*}{ ONPI 24} & $\operatorname{Rib}(H W)$ & II.887 & 15.259 & 3.372 & 28.37 & $|5.10|$ & 3.214 & 27.04 & 13.37 & 1.483 & 12.48 \\
\hline & $\operatorname{Rib}(L W)$ & II.466 & 14.378 & 2.912 & 25.4 & 13.694 & 2.228 & 19.43 & 12.759 & 1.293 & 11.28 \\
\hline \multirow[t]{2}{*}{ NYEIO0 } & $\operatorname{Rib}(H W)$ & II .887 & 13.456 & 1.569 & 13.2 & $|2.98|$ & 1.094 & 9.2 & 12.767 & 0.88 & 7.4 \\
\hline & $\operatorname{Rib}(L W)$ & II.466 & 12.318 & 0.852 & 7.43 & II.996 & 0.53 & 4.62 & II.684 & 0.218 & 1.9 \\
\hline 30 I-C-J-I (60\%) & $\operatorname{Rib}(H W)$ & I I.887 & 14.145 & 2.258 & 19 & 13.959 & 2.072 & 17.43 & 13.366 & 1.479 & 12.44 \\
\hline $30 I-S W-I$ (40\%) & $\operatorname{Rib}(L W)$ & II. 466 & 13.456 & 1.99 & 17.36 & 12.826 & 1.36 & 11.86 & 11.951 & 0.485 & 4.23 \\
\hline \multirow[t]{2}{*}{ NEWTEX BIF } & $\operatorname{Rib}(H W)$ & II.887 & 13.477 & 1.59 & 13.38 & 13.236 & 1.349 & 11.35 & 13.019 & 1.132 & 9.52 \\
\hline & $\operatorname{Rib}(L W)$ & II.466 & 12.677 & 1.211 & 10.56 & $12.23 \mid$ & 0.765 & 6.67 & II.784 & 0.318 & 2.77 \\
\hline
\end{tabular}




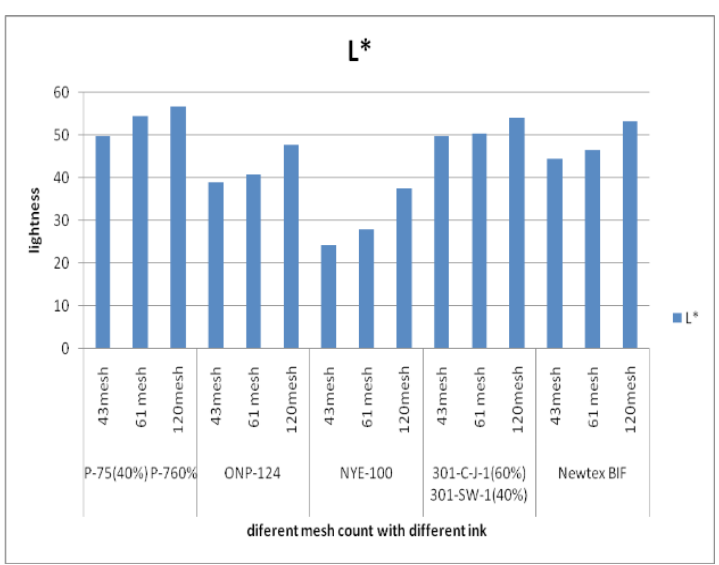

Figure 5 Lightness difference of different printed fabric under different mesh count in dot design.

\section{Analysis of different design under microscope}

Different distance, circular area, diameter, etc. was measured for printed fabric in dot design and compared with image positive under microscope. For dot design it was used 43, 61 and 120 mesh count fabric and they had 4,16 and 36 open rectangle areas at $6 \times 6 \mathrm{~mm}^{2}$ $(1600 \times 1200$ camera size $)$. In dot design there were different portions of design with different dpi. It was selected in the middle of $\mathrm{R}$ in the FUTURE written in design (adjacent to E) with $10 \times 10$ dots in $6 \times 6 \mathrm{~mm}^{2}$. For finding the accuracy dot printing dot diameter, distance between two dots and distance among three dots were measured. The measurement in image positive and the similar measurement were compared in a printed fabric by different ink under the different mesh count screen. The background coverage was assessed by the open space present in the printed fabric. Outer line sharpness was assessed by the distortion of printing ink from the outer line.

From the Figure 6, under the digital microscope, it was seen that 120 mesh counts produced a good printing effect because the dot diameter, distance between two dots and distance among three dots were almost similar like image positive. The dots diameter, the distance of two dots nd among three dots were $1.44,4,6.4 \mathrm{~mm}$ in image positive and $1.44,4$ and $6.48 \mathrm{~mm}$ in printed fabric by P-75, D-76 ink system. In 43, 61 and 120 mesh had rectangular open area 2.496,0.03374 and $0.144 \mathrm{~mm}^{2}$ respectively, and percentage of opening was $27.73,14.99$ and $12.41 \%$. Printing paste was passed through the mesh with a low amount and precisely in the allocated area of design by 120 mesh count screens because one dot was surrounded by 13 small rectangle open areas (From the Figure 12, in image positive). So, the print paste was deposited very precisely as the rectangle number was high and the area of the open rectangle was low. So, the shape of the dot in printed fabric almost was similar to the image. However, the same design on low mesh fabric like 43 and 61 were distorted the image sharpness as they had large open areas, i.e. one dot was surrounded by 8 and 6 open rectangles at 61 and 43 mesh screens respectively From the Figure 12, in image positive). So, printed fabric lost the circular shape of dots and more pests passed through the screen the. The order of printing accuracy was $120 \mathrm{MC}$ screen $>61 \mathrm{MC}$ screen $>43 \mathrm{MC}$ screen.

Dot was printed in different diameters as sometimes dot was surrounded by a fully opened rectangle area. Some yarn width increased dot dia. The diameter, in a printed fabric by 43 and 61 mesh screens, were reduced because the dot was surrounded by large open area which caused spreading of printing ink. But the scenery was different for the diameter, in a printed fabric by 120 mesh screens, was very nearer to image diameter, because dot (made by emulsion coating and UV exposure) was surrounded by very small percentage open area which resist spreading of printing ink (Figures 7-11).

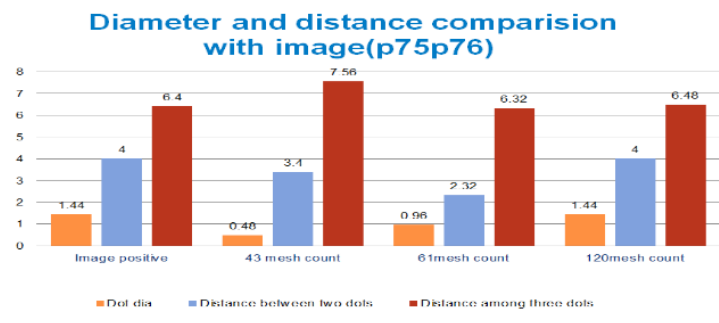

Figure 6 Diameter and distance comparison with image (p75p76).
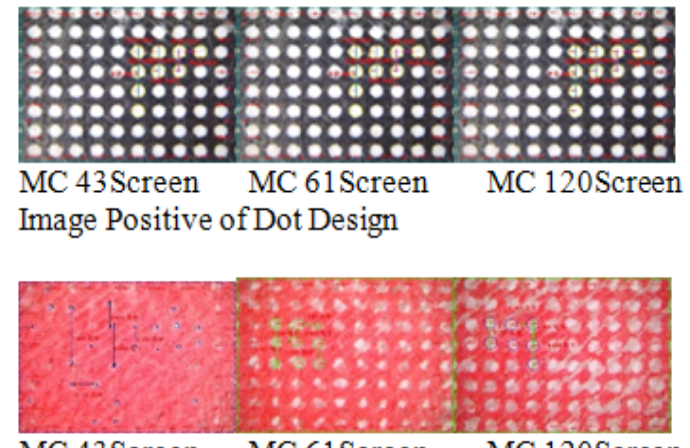

MC 43Screen MC 61Screen MC 120Screen Printed Fabric by using ink P-75(40\%) P-76(60\%)
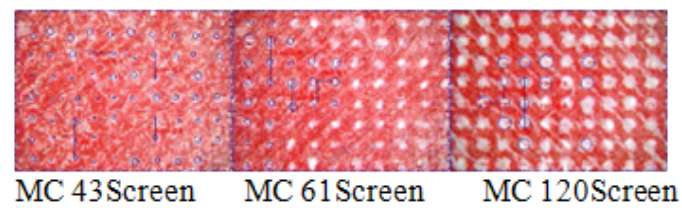
Printed Fabric by using ink ONP-124

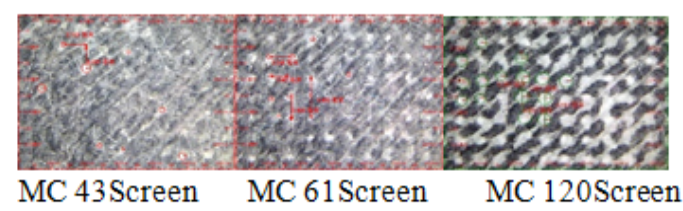

Printed Fabric by using ink NYE-100

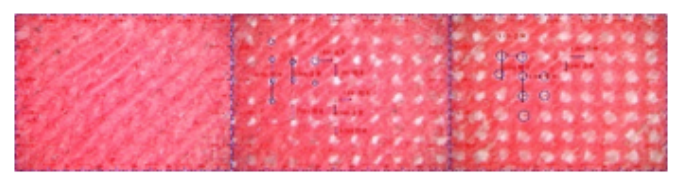

MC 43Screen MC 61Screen MC 120Screen Printed Fabric by using ink 301-C-J-1(60\%) 301-SW-1(40\%)|

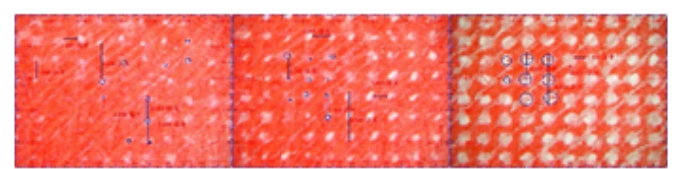

MC 43Screen MC 61Screen MC 120Screen Printed Fabric by using ink NEWTEX BIF

Figure 7 Printed fabric for dot deign under microscope (I600× 1200 pixels). 


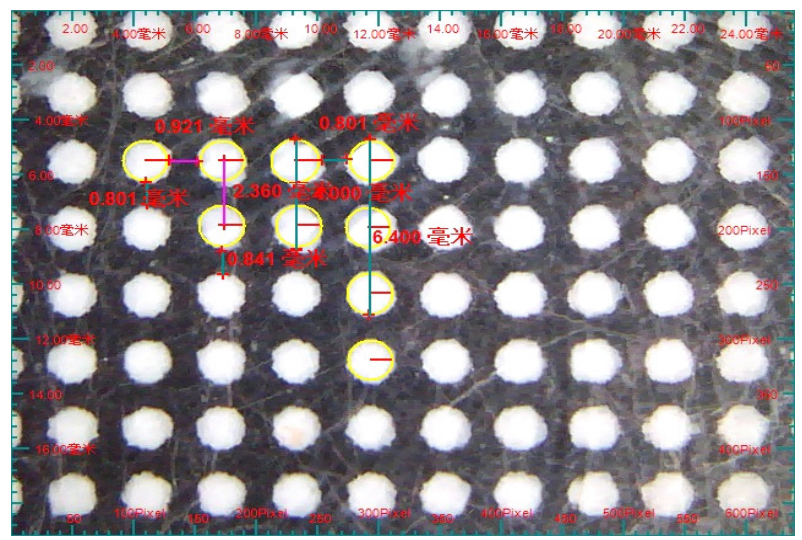

Figure 8 Image positive of dot design (640×480pixels).

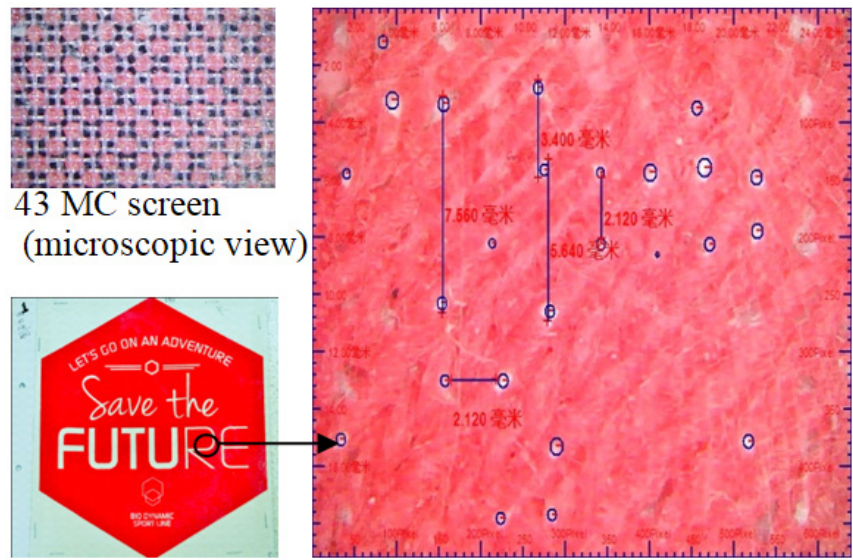

Printed fabric (Normal view)

Printed fabric (Microscopicview)

Figure 9 Image of dot design printed fabric using 43 mesh count screen (640×480pixels).

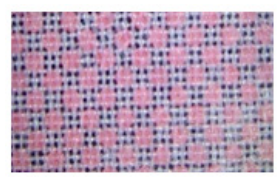

$61 \mathrm{MC}$ screen (microscopic view)

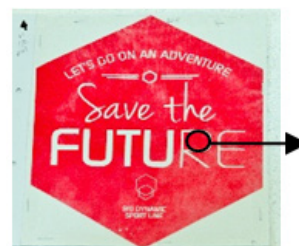

Printed fabric (Normal view)

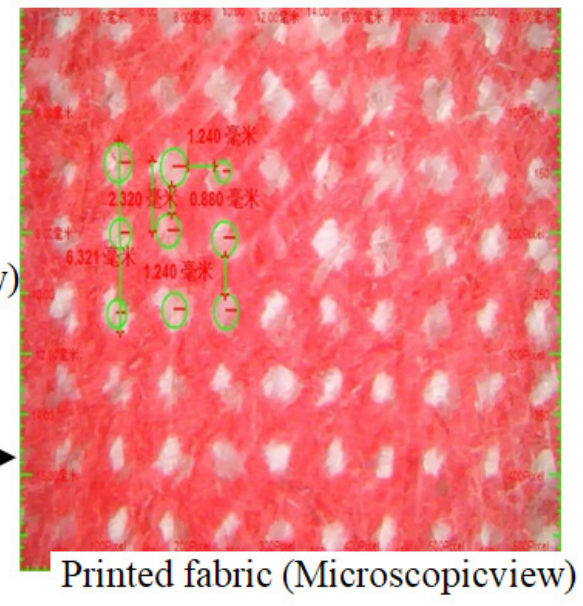

Figure 10 Image of dot design printed fabric using 61 mesh count screen (640×480pixels).

From Figure 12, it was observed that saw tooth effect decreased with the increase of MC. Outer line sharpness was almost similar to design for high MC (Table 9).

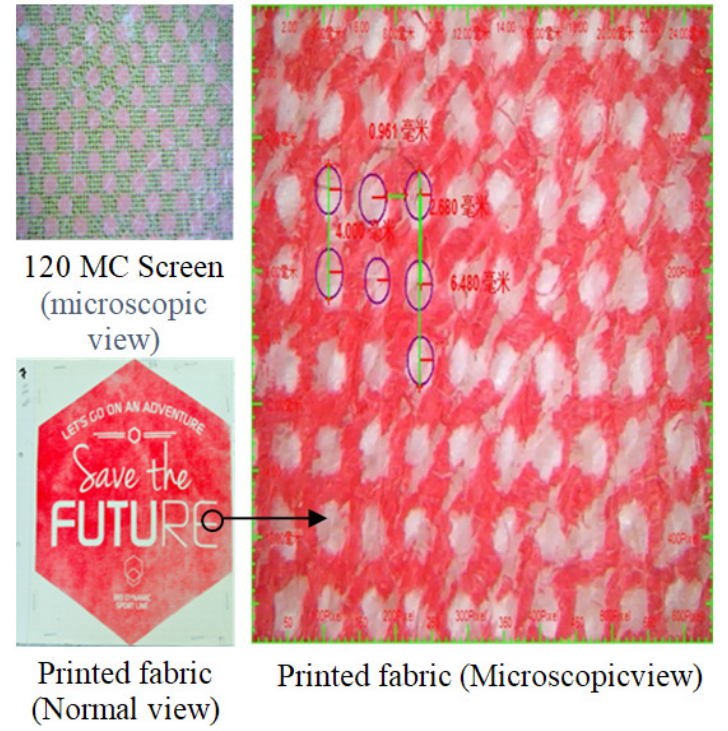

Figure I I Image of dot design printed fabric using 120 mesh count screen (640×480pixels).
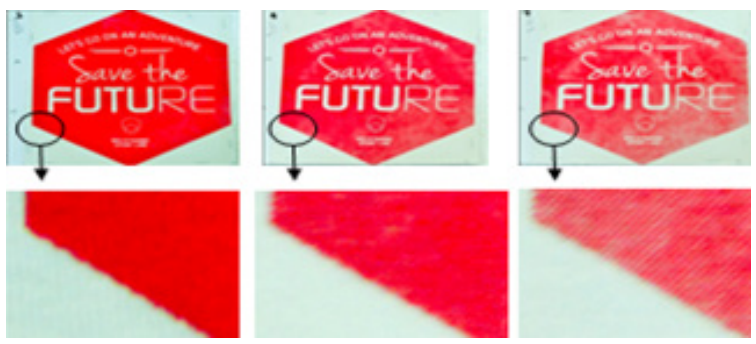

Figure 12 Saw tooth effect in dot design.

Table 9 Different distance and diameter measurement in dot design (Image Positive)

\begin{tabular}{|c|c|c|c|c|}
\hline $\begin{array}{l}\text { Design: } \\
\text { Dot } \\
\text { Positive } \\
\text { (Image-R) }\end{array}$ & $\begin{array}{l}\text { Dot } \\
\text { diameter(mm) }\end{array}$ & $\begin{array}{l}\text { Distance } \\
\text { between } \\
\text { two dots } \\
(\mathrm{mm})\end{array}$ & $\begin{array}{l}\text { Distance } \\
\text { among } \\
\text { three dots } \\
(\mathrm{mm})\end{array}$ & $\begin{array}{l}\text { Visible } \\
\text { Area }\end{array}$ \\
\hline & $\mathrm{I} .44$ & 4 & 6.4 & 100 dots \\
\hline
\end{tabular}

From Table 10, it was found that accuracy of printing was better for higher MC than lower MC by different ink deposition.

\section{Color fastness performance}

Washing Fastness, rubbing fastness and light fastness of different printed fabric under different mesh count with different ink was done.

Rubbing fastness: There was no significant change of rubbing fastness with the change of mesh count (Figure 13).

Washing Fastness: There was no significant change of light fastness with the change of mesh count (Figure 14).

Light Fastness: There was no significant change of light fastness with the change of mesh count (Figure 15). 
Table I 0 Different distance and diameter measurement in dot design Printed fabric with different ink

\begin{tabular}{|c|c|c|c|c|c|}
\hline $\begin{array}{l}\text { Ink name in } \\
\text { printed fabric }\end{array}$ & MC & Dot diameter $(\mathrm{mm})$ & $\begin{array}{l}\text { Distance Between } \\
\text { two dots }(\mathrm{mm})\end{array}$ & $\begin{array}{l}\text { Distance among } \\
\text { three dots }(\mathrm{mm})\end{array}$ & Visible area \\
\hline P-75(40\%) & 43 & $0.56,0.48,0.2$ & $3.4,5.64$ & 7.56 & All dots are not visible \\
\hline \multirow[t]{2}{*}{ P-76(60\%) } & 61 & $1.28,0.96,1.2$ & 2.32 & 6.32 & All dots are visible \\
\hline & 120 & $\mathrm{I} .44$ & 4 & 6.48 & All dots are visible \\
\hline \multirow[t]{3}{*}{ ONP-I 24} & 43 & $0.1,0.4,0.6$ & 2.8 & 5 & All dots are not visible \\
\hline & 61 & & 3.361 & 5.8 & All dots are visible \\
\hline & 120 & $1.52,1.36$ & 3.561 & 6.24 & All dots are visible \\
\hline \multirow[t]{3}{*}{ NYE-100 } & 43 & $0.64,0.88,0.32,0.96$ & 3.321 & - & All dots are not visible \\
\hline & 61 & I. $5,0.4,0.48,0.56$ & 3 & 4.48 & All dots are visible \\
\hline & 120 & I.52,I.36 & 4.161 & $6.36 \mathrm{I}$ & All dots are visible \\
\hline $30 I-C-J-I$ & 43 & - & - & - & Very few dots are visible \\
\hline \multirow[t]{2}{*}{$30 I-S W-I$} & 61 & $0.64,0.56,0.88$ & 3 & $5.76 I$ & All dots are visible \\
\hline & 120 & I.I,I.4,I.28 & 3.44 & 6 & All dots are visible \\
\hline \multirow[t]{3}{*}{ Newtex BIF } & 43 & $0.56,0.32,0.4$ & 2.08 & 5.92 & All dots are not visible \\
\hline & 61 & $0.72,0.24$ & 3.36 & 6.04 & All dots are visible \\
\hline & 120 & I.36, I. $28,1.52$ & 3.952 & - & All dots are visible \\
\hline
\end{tabular}

\section{Rubbing fastness}

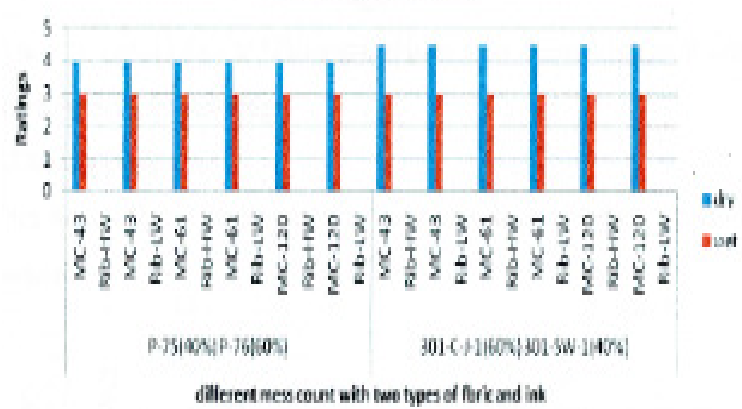

Figure I 3 Rubbing Fastness of different printed fabric under different mesh count with different ink for dot design.

WASHING FASTNESS

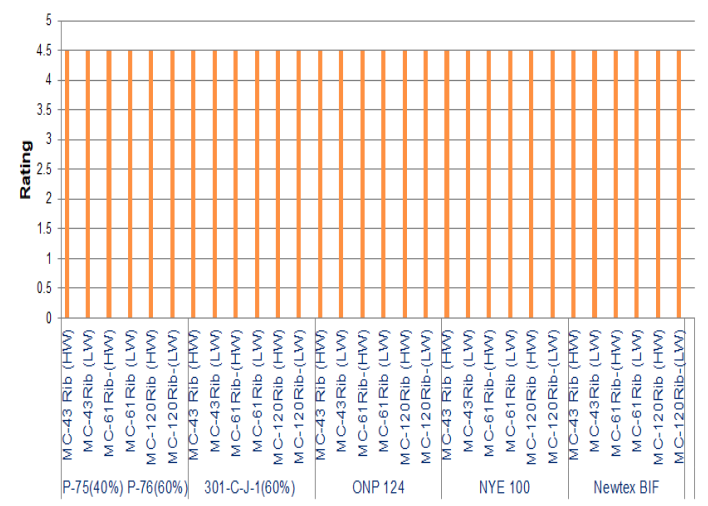

Different mesh count with different fabric and ink

Figure I4 Washing Fastness of different printed fabric under different mesh count with different ink for dot design.
LIGHT FASTNESS

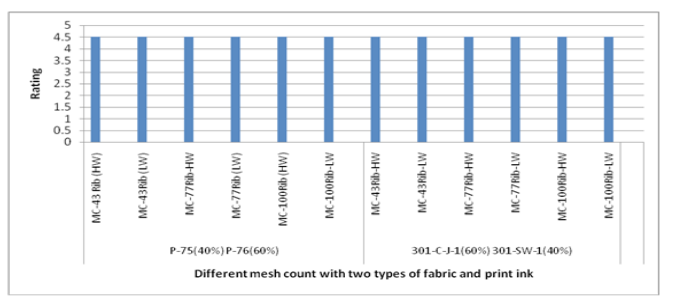

Figure 15 Light Fastness of different printed fabric under different mesh count with different ink for dot design.

\section{Conclusion}

The thesis work was done to find the mesh count effect on dot design of knit cotton printed fabric. The mesh opening area was calculated to find the amount of ink passed through, level of print detail in dot design.

With the increase of mesh count the opening space of the screen was decreased. Print screen with higher mesh opening area causes more ink deposition on the printed fabric than screen of lower mesh open area. It was also found that more ink was deposited on high GSM fabric than the lower GSM fabric and percentage of ink deposition was greater for high viscous paste than lower viscous paste.

The higher mesh count screen was capable of giving a better hand feel in cotton printed fabric than lower mesh count screen depending on types of inks.

It was found that the higher mesh opening area results in good background coverage in printed fabric. Saw-tooth effect was prominent in the lower mesh count. 
Print detail was not good in the lower mesh count. The accuracy in line size and sharpness was nearer to image positive in higher mesh count. Gradation of tone was very prominent in higher mesh count Printed fabric was lighter color with lower mesh open area screen as the ink deposition was lower using the print screen with lower mesh opening area (high mesh count screen) during printing.

Finally, higher mesh count was capable of giving high accuracy in design with lower ink consumption and good hand feel. On the contrary, lower mesh count was capable of giving good background coverage, but lost accuracy in print detail and line sharpness.

There was no change in color fastness performance of printed fabric with the change of mesh count.

\section{Acknowledgments}

I would like to express my gratitude to Orient-Chem Ltd., DysinChem Ltd. \& Dysin International Ltd for their valuable and cordial support in various aspects of the thesis work. I also grateful to the Wet Processing Lab and TTQC Lab of Bangladesh University of Textiles.

\section{Funding}

None.

\section{Conflicts of interest}

The authors have no conflicts of interest regarding the publication of this paper.

\section{References}

1. Leslie W C Miles. Textile printing, 2nd edn. 2009. 352 p.

2. Handbook for screen printers. Sefar Inc. Printing Division, Switzerland: CH-9425, Thal/SG; 1999.

3. Textile printing and the environment.

4. Leslie W C Miles. Textile printing. 2nd edn. 21 p.

5. Leslie W C Miles. Textile printing. 2nd edn. p: 44-45.

6. M Lomas, Short IG. Screen printing variables and their effect on print paste consumption. JSDC. 1999;115:262.

7. Zheng H, Zheng J. Screen printing technology. Beijing: Printing Industry Press; 2006.

8. Gai $\mathrm{MZ}, \mathrm{Pu}$ JD, Wen $\mathrm{CX}$, et al. Research on the quality of screen printing based on the UV ink. Advanced Materials Research. 2011;380:121-124.

9. Arthur D Broadbent. Basic principle of textile coloration. Society of Dyers and Colorists. 2001:460-462.

10. ISO 105-C02. Textiles: test for color fastness part C02, color fastness to washing. 1994.

11. ISO 105-B02. Test for color fastness to artificial light: xenon arc fading lamp test. 1994.

12. ISO 105-X12. Textiles: test for color fastness. Part X12, Color fastness. 1993. 